\title{
OTRA APORTACIÓN AL «DEBAT DE LES JURISDICCIONS» ENTRE BAILÍA Y GOBERNACIÓN. EL CRITERIO JURÍDICO DE DOMINGO MASCÓ
}

\author{
José Vicente CABEZUELO PLIEGO \\ Universidad de Alicante
}

Nuestra preocupación por el estudio de las instituciones forales valencianas durante el período medieval nos ha llevado en más de una ocasión a ocuparnos del tema de las injerencias jurisdiccionales, tomando como punto de referencia la Gobernación. Una primera aproximación a la cuestión la planteamos en el $X V^{\circ}$ Congreso de Historia de la Corona de Aragón celebrado en Jaca en $1993^{2}$, donde el objeto de análisis se cifró en una concordia firmada en 1376 entre los titulares de la Bailía y la Gobernación para poner fin al rosario de acusaciones de mutua injerencia que sufrían ambas magistraturas de la mano de la otra y que impedía una correcta y sobre todo rápida solución de los procesos. Pero como poníamos de manifiesto en ese trabajo, pese a la voluntad política personal de los firmantes, la propia evolución jurisdiccional de cada una de las instituciones, ajenas a cualquier normativa preestablecida que limitase jurídicamente sus fronteras, impedía la fructificación de una verdadera pax officiorum. A tan importante dificultad se unía otra: el componente personal existente en el gobierno de cada institución, que hacía que determinados caracteres por diversidad de

1 Este trabajo se ha realizado en el marco del proyecto de Investigación titulado Administración real y municipal en el reino de Valencia durante la época foral medieval, con número de referencia GVB-ES-15-023-96, financiado por la Conselleria de Cultura, Educació i Ciència de la Generalitat Valenciana.

2 CABEZUELO PLIEGO, J.V., "Un intento para resolver ciertos conflictos jurisdiccionales entre la Gobernación y la Bailía General del reino de Valencia. Acerca de la Concordia de 1376", en Actas del XVo Congreso de Historia de la Corona de Aragón, Zaragoza, 1996, T. I, vol. $2^{\circ}$ (Crónica y ponencias), pp. 55-65. 
motivos - linaje, prepotencia personal o prepotencia institucional - tuviesen una mayor o menor inclinación hacia actitudes beligerentes o reconciliadoras.

Este conflicto de jurisdicciones, surgido a la par que los propios oficios, se desató con gran virulencia a finales del siglo XIII, cuando la hasta la fecha indiscutible primera magistratura del reino, la Procuración, vio recortadas algunas de sus competencias en favor de la Bailía y de las magistraturas municipales ${ }^{3}$. El fortalecimiento de éstas sobre antiguas parcelas de poder de aquélla nunca fue del todo superado por procuradorers y gobernadores, puesto que tal pérdida repercutía tanto sobre su prestigio como sobre sus caudales -institucionales y personales-4 ${ }^{4}$. Pero lo más curioso es que la Corona, promotora de los cambios, no se ocupó nunca de establecer no ya un imposible vademécum jurisdiccional de todas y cada una de las magistraturas, inviable a todas luces porque en muchos casos el derecho sancionador iba por detrás del propio hecho, sino ni tan siquiera un catálogo que no fuese general de intervenciones privativas y de supuestos permitidos, con lo que ya por convicción ya por omisión la Corona permitió que la injerencia se situase casi al lado de la competencia ${ }^{5}$.

Durante la primera mitad del siglo XIV tales conflictos fueron ciertamente numerosos, pero será a partir de 1350 cuando alcancen una elevada cota de crispación. La intervención real se hizo necesaria para poner fin a la guerra de jurisdicciones que se vivía en el reino de Valencia, pero la prudencia de las sentencias y el incumplimiento de los castigos por quebranto de la observancia de tales sentencias no atajó el problema, que muy al contrario disparó.

De un lado debemos tener en cuenta que los distintos gobernadores valencianos de la segunda mitad del Trescientos desobedecieron de forma discreccional el contenido de distintas pragmáticas editadas de antiguo que limitaban su actuación, derivando tales competencias a la Bailía. Es el caso de las cuestiones relativas a las minorias religiosas confesionales, musulmanes y judíos, y todo aquello que giraba en torno a ellas, que pese a que desde finales del siglo XIII quedaron en lo genérico dentro de las atribuciones de la Bailía, con disposiciones legales que así lo apuntaban, no cesarán de verse envueltas en conflictos ${ }^{6}$. El motivo era económico, pues las multas impuestas sobre una población islámica ciertamente numerosa sujeta a unos controles legales muy rígidos alcanzaban sumas considerables que permitían, en el marco de la más absoluta legalidad, asegurar la percepción de un salario vinculado a la propia capacidad de saneamiento de las arcas de la magistratura, y, desde un po-

3 CABEZUELO PLIEGO, J. V., La Curia de la Procuración. Estructura de una magistratura medieval valenciana, Alicante, 1998, pp. 129-151.

4 Ibídem, pp. 55-77. Id., «El poder real en la Murcia aragonesa a través del oficio de la Procuración, 1296-1304», en Actas del Congreso Internacional «Jaime // Setecientos años después», Alicante, 1997, pp. 94-97.

5 CABEZUELO Pliego, J.V., La Curia de la Procuración ..., pp. 223-232. PÉREZ GARCíA, P., "Origen y configuración de una magistratura urbana de la Valencia foral: el Justicia Criminal», en Estudis. Revista de Historia Moderna, 13, Valencia, 1987, pp. 44.

6 CABezUelo Pliego, J.V., La Curia de la Procuración ..., pp. 129-151. 
sicionamiento nada legal pero sí real, la apropiación indebida de peculio via multas y composiciones no anotadas convenientemente en los libros de cuentas del escribano.

Lo cierto y verdad es que ni por apelación podía intervenir la Gobernación en asuntos cuyo tratamiento incumbía a los bailes generales, como ya quedó establecido en $1340^{7}$. Pero aun así la inmiscusión, o lo que es lo mismo la desobediencia a la legislación existente, se convirtió en un hecho cotidiano, aunque como veremos en algunos casos el problema era tanto falta de legislación como permisibilidad de la autoridad correspondiente.

Al respecto del primero de los asuntos, durante los inicios del gobierno de Pedro el Ceremonioso quedó convenientemente establecido que Bailía y Gobernación eran dos instituciones paralelas que se ocupaban de asuntos distintos, con lo que no debía existir ningún derecho de superioridad de una con respecto a la otra; ello por los constantes abusos de la segunda. Aun así, la Gobernación, o mejor, sus titulares, hicieron caso omiso a tales pragmáticas y continuaron penetrando en el terreno jurisdiccional de la Bailía. En julio de 1350 Pedro IV recriminaba a García de Loriz, recién electo cabeza de la magistratura, sus desmedidas e irrespetuosas actuaciones al intervenir ilegalmente sobre un asunto correspondiente a la Bailía, el de los musulmanes. El entonces todavía procurator ${ }^{8}$, no sólo había llamado a su Tribunal a mudéjares del país para expedirles licencias de viajes, capturado a quienes no las portaban así como a otros por diversas razones, junto con sus bienes, y pactado con ellos su libertad por una determinada cantidad de dinero, sino que incluso llegó a revocar sentencias emitidas desde la Bailía ${ }^{9}$. El procurador aducía la existencia de una legislación insuficiente en esta materia, con lo que la injerencia había de ser disculpada. Pero nada más lejos de la realidad. Al año siguiente era de nuevo reprendido por haber concedido licencias para acaptar a algunos moros y capturado a quienes no las portaban, cuando desde 1337 era una causa que correspondía a la Bailía ${ }^{10}$.

Fueron constantes los abusos del gobernador, las quejas del baile y las reprimendas del rey ${ }^{11}$, pero como hemos apuntado muchos eran los factores que impedían que se llegase a una solución final que terminase con el problema de las disputas. El pri-

7 Ibidem, pp. 229-230.

8 Acerca del cambio de denominación de la institución cf. ibídem, pp. 90-92.

9 Archivo de la Corona de Aragón —en adelante ACA - Cancillería -en adelante C-, reg. 1064, f. 107v. y f. 108r. (1350, julio, 2).

10 Archivo del Reino de Valencia -en adelante ARV—, Real Cancillería —en adelante R-, reg. 687 , ff. 25v.-26r. ALANYA, L. (ed.), Aureum opus regalium privilegiorum civitatis et regni Valentie cum historia cristianisimi regis Jacobi ipsius primi conquistatoris —en adelante AO-, Valencia, 1515, reimpresión facsímil Valencia, 1972, con índices preparados por M.D. CABANES PECOURT, f. 120r. (1351, mayo, 16).

11 ACA, C, reg. 1068, ff. 74v.-75v. (1356, enero, 31); ff. 73r.-74v. (1356, febrero, 3). ACA, C, reg. 1154, ff. 16v.-17r. (1356, marzo, 12). ACA, C, reg. 1079, f. 70r.-v. (1367, junio, 19). ARV, R, reg. 687, f. 90r.-v. (1384, febrero, 10). ARV, R, reg. 688, ff. 133r.-136r. y ff. 188r.-190r. (1386, febrero, 15). ARV, R, reg. 688 , ff. 136r.-137v. (1388, noviembre, 23). ACA, C, reg. 2223, f. 12r. y 13v. (1397, junio, 28). ACA, C, reg. 2223, f. 13v. y ARV, R, reg. 688, f. 207r.-v. (1399, junio, 30). Etc. 
mero, la escasa disposición real a llevar a la práctica de forma efectiva los castigos con los que advertía en sus pragmáticas a quienes transgrediesen las reales órdenes. Las multas pecuniarias, la apertura de expedientes disciplinarios que terminaban con la expulsión deshonrosa del oficio, la caída en la ira e indignación regia, todo ello nunca ejecutado, envalentonaba a los oficiales de la Curia Gubernationis a continuar con esas prácticas. Pero junto a la escasa voluntad de la Corona, se dieron otras causas que ayudan a explicar el fenómeno, tales como las confusiones existentes en la propia legislación y la parquedad de la misma en determinados supuestos, que aprovechaban los litigantes para atraerlos al terreno de sus competencias a través de la disputa. El 1358 Pedro el Ceremonioso había de hacer marcha atrás en la concesión de una comisión a García de Loriz, gobernador, al saber que el servicio que le encomendaba, la investigación y punición de los correos que actuasen de modo fraudulento, quedaba dentro de las competencias del baile general valenciano ${ }^{12}$.

En muchos casos era la propia Corona la que desconocía el campo de competencias de cada una de sus magistraturas y solicitaba a una la intervención en un asunto que correspondía a la otra, ya por via ordinaria ya a través de comisarios. Esta última via, la comisión, fue muy criticada, al vulnerarse de forma consciente el ámbito jurisdiccional de un oficio y dar pie al otro para intervenir en supuestos similares ya sin licencia real para ello. Es lo que sucedió unos años después cuando Pedro IV dispuso que las apelaciones de los oficiales reales del territorio valenciano, así como las sentencias o juicios emitidos de éstos, fuesen entregados al gobernador del reino o a su lugarteniente. El baile general discrepó de tal provisión al entender que con ella los oficiales de la Gobernación podían interferir en asuntos correspondientes a la Bailía, con lo que esta magistratura quedaría en inferioridad con respecto a la Gobernación. El rey, entonces, se vio en la necesidad de invalidar temporalmente la pragmática hasta que una vez en el reino de Valencia y escuchadas ambas partes, tomase una decisión final; mientras tanto tales causas pasarían a ser resueltas en la Curia regia o en su defecto en la del infante primogénito ${ }^{13}$. Este asunto de las comisiones fue tratado en una concordia firmada por ambas instituciones en 1376, pactanto al respecto que sólo ellos serían competentes en los asuntos que quedasen dentro de su jurisdicción ${ }^{14}$, aunque como veremos sin ningún resultado. $Y$ es que los perfiles jurisdiccionales eran tan angulosos y la normativa tan exigua que resultaba casi imposible no injerir actuando incluso desde el espíritu de la buena fe. En 1378 el baile general valenciano acusaba a Olf de Pròxida, gobernador, de inmiscuirse en asuntos pertenecientes a la Bailía General, pero aquél no había hecho otra cosa que actuar por mandato del rey. Siguiendo una real orden de 12 de noviembre del año anterior por la que Pedro IV había dispuesto que se procediese contra aquellos que portando comisión real o del primogénito componían con delincuentes que merecían por la gravedad de sus delitos penas mayores, y atendiendo a que las remisiones sobre esos crímenes sólo podían ser

12 ARV, R, reg. 659 , ff. 90v-91v. (1358, mayo, 1).

13 ACA, C, reg. 1092, f. 125v. (1375, octubre, 30).

14 CABEZUELO PLIEGO, J.V., «Un intento por resolver ..., p. 61. 
pactadas por el rey, su primogénito y el gobernador del territorio, Olf de Pròxida entró a juzgar a un judío de Alzira inculpado de crímenes de ese calado. El baile general le acusó de injerencia y Pedro IV hubo de disculparle señalando que pese a la mentada ordenanza tal causa correspondía a la Bailía ${ }^{15}$.

Si bien, en otras ocasiones, y de forma consciente, los reyes alentaban a sus oficiales al cumplimiento de sus obligaciones, pese a que tal observancia traía consigo la consabida injerencia. Así obró Juan I en 1393 cuando tras haber ordenado a los oficiales de la Gobernación no intervenir en los asuntos de las aljamas sarracenas de Onda, Tales y Artesa, a petición del propio colectivo musulmán, sin la presencia del baile local, dispuso que atendiesen de modo inmediato las causas que fuesen movidas en esas aljamas y que perteneciesen a su jurisdicción no obstante el mandato anterior ${ }^{16}$. El hecho de intervenir en litigios de mudéjares, aun teóricamente dentro de la legalidad jurisdiccional, suponía para el juez instructor un gran quebranto, ya que cualquier matiz hacía que este tipo de causas quedasen dentro del arco jurisdiccional de la Bailía y desde ella se acusase a la Gobernación de intervencionismo.

El problema, como decimos, no era en absoluto baladí, puesto que tal complicación jurisdiccional hacía que la propia sociedad valenciana desconociese el alcance real de sus instituciones y dudase en más de una ocasión acerca de la conveniencia o no de introducir un pleito en uno $u$ otro Tribunal. Tal sucedió en las Cortes de Valencia de 1403, cuando el brazo militar presenta como agravio la encarnizada disputa existente entre Bailía y Gobernación en lo tocante a la concesión de licencias para acaptar concedidas a los vasallos musulmanes del citado brazo, así como a las licencias concedidas a "les mores avols fembres que han acostumat servir los moros de les aljames", y solicita del rey una resolución definitiva sobre el tema, ya que ellos dudan cual de las dos magistraturas es la legalmente competente. Lógicamente Martín I el Humano hizo recaer el peso de tales causas sobre la Bailía". Dándose también casos en los que la complicación jurídica para conocer de qué lado debía caer la competencia era tan importante que se optaba por una decisión salomónica que vinculaba a ambas instituciones en el conocimiento, resolución y beneficio económico, si es que lo había, de la causa en litigio. Así se observa en los cuadernos de cuentas de los bailes generales, cuando, por ejemplo, en 1364 se pactó una composición entre baile y gobernador con Mahomat el Manloch, moro de Paterna, por diversos delitos cometidos por éste en la ciudad de Valencia. Al conocer de esos crímenes el baile lo mandó detener, si bien el gobernador «feu aquell emparar dient que per o com lo dit moro se daya èsser de Paterna que la punició pertanya a ell e a son officis. Ante la polémica surgida ambos oficiales decidieron que el montante obtenido por esa via, mil

15 ACA, C, reg. 974, ff. 187v.-188v. (1378, marzo, 6).

16 ACA, C, reg. 1950, f. 179r. (1393, noviembre, 14).

$17 \mathrm{ARV}, \mathrm{R}$, reg. 630, ff. 286r.-287r. (1403, septiembre, 28). Furs e Ordinations fetes per los gloriosos reis d'Aragó als regnícoles del Regne de València, Valencia, Imprenta de Lamberto Palmart, 1482, ed. facsímil, Universidad de Valencia, 1977, rúb. V, cols. $1^{\mathrm{a}}$ y $2^{\mathrm{a}}$, p. 424. 
sueldos, "fos partit per eguals parts" "18. Mientras que en 1372 Francesc Marrades anota haber recibido de Zohora, mora natural de Eslida, hija de Abdelaziz Marxich, cien sueldos de los trescientos con que se pactó la remisión de su delito, yendo a parar los otros doscientos, a partes iguales, a manos de Joan de Salars, procurador del señor de Bétera, que era el maestre de Calatrava, y de Pere de Thous, lugarteniente del gobernador del reino. Dicha partición se realizó atendiendo a que el mentado lugarteniente reivindicaba para la Gobernación dicha causa argumentando que la delincuente era acusada de adulterio y de acaptar limosna sin licencia. Mientras que el procurador señorial también reivindicaba su parte del dinero al estar la inculpada durante la remisión en Bétera y existir una pragmática que decía que los mudéjares que fuesen encontrados en ese lugar y sobre ellos se compusiesen pecuniariamente sus crímenes, la mitad de la composición recaería sobre el señor de Bétera. Atendiendo a esta pragmática la mitad de la cantidad producto de la composición correspondía al maestre de Calatrava, así como atendiendo a la legislación dicha causa estaba del lado de las competencias de la Bailía, pero como exponía el baile «fon convengut entre nosaltres quels dits CCC solidos fossen departits entre nosaltres en la forma dessus recomptada» ${ }^{19}$. Desde luego en ambos casos el pacto se produce, sin duda, para no retardar el proceso.

Así se obró también en 1408 cuando en un asunto de defensa de las regalías -hurto de lana-Martín el Humano dipuso que fuesen baile y gobernador quienes al unísono se ocupasen de la resolución de ese asunto sin perjuicio para ninguno de los oficios ${ }^{20}$. Aunque en otros casos las disputas eran zanjadas de forma categórica, arrebatándolas a los litigantes y entregándolas en forma de comisión a jueces nombrados directamente por el rey, tal y como hizo Pedro IV en 1377 cuando las dos Gobernaciones valencianas, citra y ultra Sexonam se vieron conmocionadas por querellas constantes entre bailes y gobernadores ${ }^{21}$.

Hemos visto, pues, que los litigios jurisdiccionales fueron constantes entre Bailía y Gobernación durante toda la segunda mitad del siglo XIV y primera década del XV; litigios, aunque parezca mentira, sustentados en una argumentación jurídica más o menos razonable. Si bien, desgraciadamente, en la mayoría de los casos sólo cono-

18 ACA, Real Patrimonio —en adelante RP-, Maestro Racional —en adelante MR-, reg. 1709, f. $19 \mathrm{v}$.

19 ACA, RP, MR, reg. 1713, f. 12r.-v.

20 ACA, C, reg. 2237, f. 59v. (1408, octubre, 24). CABEZUELO PLIEGO, J.V., "Un intento por resolver ..., p. 65 .

21 Para solucionar este asunto fueron nominados por Pedro el Ceremonioso dos jueces, Miquel de Piera y Bernat d'Alpicat, con potestad para llamar a las partes y celebrar los procesos «breviter, simpliciter et de plano", es decir, lo más rápidamente posible. ACA, C, reg. 1096, f.153r.-v. (1377, octubre, 26). 
cemos eso, la disposición real ante una queja, no la apoyatura legal de cada una de las partes, hecho que nos permitiría alcanzar a comprender los mecanismos de las magistraturas para defender sus prerrogativas y mantener su independencia ante injerencias de otras. Lo cierto es que hemos localizado uno de ellos, fechado a finales del reinado de Martín el Humano, y centrado en un asunto muy típico, la jurisdicción sobre los musulmanes del país. En el verano de 1408 Nicolau Pujada, baile general, siente vulnerados los derechos de la magistratura que regenta por la actuación del gobernador, Guillem Ramon de Montcada, quien, al parecer del baile, le impedía el uso de la jurisdicción civil y criminal sobre los moros de Onda, cuando, según reivindicaba, pertenecían a su oficio tras provisión real de 1298 donde se apuntaba que los sarracenos de realengo y de personas religiosas del reino de Valencia quedaban dentro de las competencias de la Bailía. El rey vio tan claro el asunto que no hizo sino reprender fuertemente al gobernador amenazándole con multa pecuniaria de mil florines de oro $^{22}$.

Lo cierto es que esta pequeña disputa en Onda originó otra de mayor calado en la misma población. En ese tiempo se desató un nuevo litigio acerca de a cual de las dos magistraturas correspondía el proceso sobre ciertos oficiales de ese municipio. A fines de ese verano el baile capturó y puso en la prisión común de la ciudad de Valencia a Llop d'Esparça, lugarteniente del baile de Onda, y Miquel Soriano, justicia de esa villa, acusados ambos de haber hecho resistencia al lugarteniente del baile general. Nicolau Pujada entendió que se trataba de un asunto a él concerniente y escribió al gobernador para que se retirase de inmediato. Pero Guillem Ramon de Montcada le respondió, a juicio del baile de modo descortés, el 8 de noviembre que tal causa era claramente competencia de la Gobernación, por tratarse de un asunto de resistencias a oficiales regios ${ }^{23}$. Además, que pese a haberle presentado la real orden fechada en septiembre de ese año y mencionada líneas atrás acerca de las competencias de la Bailía en materia de sarracenos, el documento fue considerado como sospechoso por el justicia de Onda, uno de los inculpados, con lo que Montcada estimó que hasta que no se procediese a su análisis jurídico la Bailía no debería intervenir. A tales considerandos respondió el baile al día siguiente acusando a la Gobernación de prepotencia, al considerarse superior al resto de instituciones valencianas, incluyendo la Bailía. Pujada fue a más al apuntar «E sia car e notori que nós e nostre offici haver gran preheminencia, conexenca e superioritat per furs e privilegis en los batles locals e senyaladament en los justícies, com nós haiam fet per lo senyor rey les eleccions de aquells e e en poder nostre hajen a dar compte e rahó de lur administració", siendo por ello, a su juicio, que desde la Bailía General se podía punir a los oficiales municipales. De todos modos, bien sabía Pujada que esa argumentación la tenía perdida, pues si era verdad que la Bailía se ocupaba de recibir el juramento de los justicias tras

22 ACA, C, reg. 2237, f. 49v. (1408, septiembre, 10).

23 El gobernador argumentaba "Stil de la Governació». Cf. CABEZUELO PLIEGO, J.V., La Curia de la Procuración ..., p. 90. 
su nombramiento ${ }^{24}$ así como sus cuentas, también lo era que correspondía a la Gobernación, ya desde los tiempos de la Procuración, la punición de esos oficiales ${ }^{25}$. Es por ello por lo que el baile intentó además corregir la acepción que vinculaba la causa a la Gobernación, cuando señalaba que exactamente no se debía procesar a los incupados de resistencia a oficiales del rey sino por inobediencia y perturbación, y tal punición recaía en la Bailía atendiendo unos privilegios de Pedro el Ceremonioso de 15 de julio de 1340 y 7 de abril de 1384 en que ordenaba al gobernador que en todos los asuntos concernientes a la Bailía no se entrometiese por via de apelación o recurso.

Nicolau Pujada también arremetió contra la interpretación que hacia Montcada del Stil de la Governació. A su juicio el gobernador únicamente sería competente en materia de oficiales públicos sobre los que pudiese argumentar derecho de superioridad, con lo que cualquier vínculo con la Bailía quedaba cerrado, al ser ésta una institución pareja en importancia. Igualmente consideraba el compendio de competencias expuestas en el Stil como relativamente novedoso. En este sentido dirá de él «no es antich ni es dels Stils per vostres predecessors en vostre offici memorieats", pero sobre todo que no podía ir en contra de los privilegios, provisiones y pragmáticas sanciones concedidos por los reyes de la Casa de Aragón a la Bailía. El baile, por tanto, afirmaba ser de su competencia tal causa, como lo hubiese sido de la de sus predecesores en el cargo, pero que incluso considerando el argumento expresado en el Stil de la Governació tampoco correspondería a esa oficina, puesto que en el caso de que «aquell qui primerament se preocupara la causa conexera" pactado en la Concordia de 1376, el mandamiento de prisión contra el justicia y el baile de Onda fue dado por él, no por Montcada, a pesar de que fuese denunciado ante la Gobernación por el procurador fiscal. Por todo ello entendía Pujada que se trataba de una causa adscrita a sus competencias, pero que en caso de que no lo entendiese así Montcada aceptase al menos el arbitraje del rey o del abogado fiscal, «lo qual es jutge per lo dit senyor assignat dels debats qui son entre nosaltres" ${ }^{26}$.

No tardó en contestar Guillem Ramon de Montcada, quien consideró que su intervención estaba más que justificada atendiendo a que dichos oficiales habían hecho ferma de dret ante él por razón del auxilio que Bertomeu Miralles, lugarteniente del gobernador en las tierras de la Plana, prestó a su homólogo del baile a instancia y requerimiento de éste. Además, el gobernador apuntaba que lo que se había producido en Onda era una resistencia a oficiales reales, siendo él el único competente en ese tipo de delitos, tal y como se le había reconocido en una actuación similar hacía escasos días en Chelva. El gobernador estaba seguro de su actuación, creyendo incluso que quien incurría en ilegalidad era el baile al tratar de diferenciar entre «resistencia» e «inobediencia», pero de todos modos se ofrecía al arbitrio real ${ }^{27}$.

\footnotetext{
24 CABEZUELO PLIEGO, J.V., «El poder real ..., p. 94 y doc. n. $\cong 10$.

25 CABEZUELO PLIEGO, J.V., La Curia de la Procuración ..., pp. 210-215.

26 ARV, R, reg. 687, ff. 110r.-115r.

27 ARV, R, reg. 687, ff. 116v.-118r. (1408, noviembre, 19).
} 
Como ambos magistrados se encontraban en Valencia, la carta del gobernador pronto tuvo respuesta por parte del baile, que al día siguiente, 20 de noviembre, le contestaba que él fue quien capturó a los mentados oficiales a instancia del procurador fiscal del rey, y que el gobernador, yendo en contra de una orden real, los sacó de la cárcel, lo que habían aprovechado los acusados para marcharse de Valencia ${ }^{28}$.

El conflicto parecía no tener límites cuando a los pocos días Martín I ordenaba al gobernador no observar el contenido de una carta fechada el 17 de septiembre por la que le mandaba no interferir en el asunto de los oficiales de Onda; carta que parece fue embargada y conseguida de modo fraudulento ${ }^{29}$. El 27 de noviembre Guillem Ramon de Montcada contestaba a las acusaciones del baile señalándole que debía ser el rey quien determinase a quien de ellos correspondía la causa, y que mientras que él no había hecho nada al respecto desde la Bailía se había citado mediante crida pública a los inculpados. El gobernador era de la opinión que la insistencia del baile debería ser considerada como crim d'usurpació. $Y$ entonces se entra en una delimitación peligrosa, saber cual de las dos instituciones era más principal, pues Montcada estaba ciertamente molesto con que se considerase que "lo offici de la Batlia es principal e al dit senyor rey inmediats y no se mencionase el suyo, indicando de forma altiva que "si del offici de la Governació açó no es dit o affermat, o es duptat, seria duptar si la neu es blanqua", con lo que pedía a Pujada que anulase la crida y esperase el dictamen real ${ }^{30}$. Hubo de ser el rey quien dispusiese, aunque no lo hizo personalmente, dejando el asunto en manos de un comisario, de nombre Joan Mercader ${ }^{31}$.

El punto y final a todos estos conflictos jurisdiccionales entre Bailía y Gobernación estaba lejano. La parquedad de la normativa competencial de cada magistratura, que daba pie a interpretaciones por parte de sus titulares, era sin duda uno de los elementos condicionantes de la problemática. Lo cierto es que en muchos casos los litigios eran utilizados una vez resueltos como referentes legales que servían para perfilar el todavía muy amplio margen de discreccionalidad jurisdiccional de buena parte de las instituciones valencianas. También, aunque en menor medida, era importante la existencia de memoriales reconocidos, más o menos exhaustivos, de las competencias con que contaba cada oficina, elaborados a base de la adición de los priviliegios competenciales y de las resoluciones de algunos de los recursos planteados a lo lar-

28 ARV, R, reg. 687, ff. 115v.-116v.

29 ARV, $R$, reg. 687 , ff. $120 \mathrm{r} .-121 \mathrm{r}$.

30 ARV, R, reg. 687, ff. 118r.-119r.

31 En febrero del año siguiente Martín I escribía a Guillem Ramon de Montcada reprendiéndole por el hecho de haber liberado de su prisión a los inculpados del asunto de Onda, así como a otros, presos por el baile general como un sarraceno del valle de Segó llamado Ahmet Alpescat. Le ordenaba entonces que devolviese a dichos individuos a la cárcel hasta que el comisario real discerniese a cual de las magistraturas correspondía la causa. ARV, R, reg. 687, ff. 122v.-123v. (1409, febrero, 25). 
go del período. Con ese espíritu apareció a mediados del Trescientos el Stil de la Governació de Arnau Joan ${ }^{32}$. Este tipo de trabajos había de ser, obviamente, obra de juristas de reconocido prestigio que además conociesen los entresijos de la institución cuyas atribuciones pretendían compendiar. Éste, desde luego, es el caso de Arnau Joan, que además de afamado abogado valenciano era cuando escribió su opúsculo asesor de la Procuración. E igualmente será el de Domingo Mascó, autor de un compendio de causas susceptibles de disputa entre Bailía y Gobernación.

Domingo Mascó fue un notable jurista de finales de Trescientos y principios del Cuatrocientos en la capital valentina. Descendía del linaje de los Mascó, asentados en el reino desde prácticamente la época de la conquista, apareciendo miembros de esta familia al frente de alguna de las más importantes magistraturas urbanas ${ }^{33}$. Linaje, a juicio de R. Narbona, que alcanzó la condición nobiliaria en el siglo XIV ${ }^{34}$. Con respesto a nuestro personaje, el citado autor nos to presenta como hijo de Pere Mascó, conseller por la parroquia de San Juan en 1356 y 1368 y señor de Burjassot. Sucedió a su padre en parecidos cargos de responsabilidad municipal desde la década de 1370: jurado por parte de la parroquia de San Nicolás en 1378, conseller por Santa María al año siguiente, jurado en 1386 y conseller por la de San Lorenzo en $1394^{35}$. Al tiempo que desde principios de la década de 1380, en su calidad de doctor en leyes, comenzó a ocupar ciertos cargos de gran responsabilidad, y lógicamente gran proyección, dentro del mundo del Derecho valenciano. Si el 28 de febrero de 1380 alcanzaba a ser nombrado asesor de la Bailía General, oficio que le fue confirmado al poco —el 25 de noviembre de ese año y algo después por Pedro el Ceremonioso ${ }^{36}$-, en esas mismas fechas actuaba como abogado fiscal de la ciudad y reino en sustitución de Bernat d'Alpicat, que pasó a ocupar la Asesoría de la Gobernación vacante tras la renuncia del hasta entonces titular Ramon $\mathrm{Nebot}^{37}$.

Desde esas fechas la estrella de Mascó fue in crescendo, llegando incluso sus éxitos hasta la Curia regia. Domingó Mascó se convirtió entonces en consejero real, alcanzando el punto más alto de su fama cuando fue nombrado por Juan I vicecanciller para el reino de Valencia, con un salario anual de diez mil sueldos, tras la reestructu-

32 Acerca de esta obra cf. Furs e Ordinations fetes ..., pp. 519-521. FERRÁN SALVADOR, V., Arnaldo Juan y su Still de la Governació, Valencia, 1936. BENEYTO PÉREZ, J., "Arnaldi Joannis opusculum», en Boletín de la Sociedad Castellonense de Cultura, XVIII, Castellón, 1936, pp. 94-106. LALINDE ABADÍA, J., La Gobernación General en la Corona de Aragón, Zaragoza, 1963, pp. 395-397. CABEZUELO PLIEGO, J.V., La Curia de la Procuración ..., pp. 85-93.

33 ROCA TRAVER, F. A., El Justicia de Valencia (1238-1321), Valencia, 1970, p. 478.

34 NARBONA VIZCAÍNO, R., Gobierno político y luchas sociales, Estrategias de poder del patriciado urbano. La ciudad de Valencia (1356-1419). Tesis Doctoral, Facultad de Geografía e Historia, Universidad de Valencia, 1988, I, p. 352. Gentileza del autor.

35 lbidem.

36 ACA, C, reg. 1920, f. 77v. (1387, julio, 5). Oficio por el que percibía anualmente la cantidad de quinientos sueldos, tal y como se refleja en las cuentas de la magistratura. ACA, RP, MR, reg. 1376, ff. 183r.-184r. (año 1382) y ACA, RP, MR, reg. 1718, f. 180r.-v. (año 1384).

37 ACA, C, reg. 976 , ff. 35v.-36r. (1381, marzo, 26). 
ración gubernativa operada por entonces que originó la aparición de tres Vicecancillerías para un mejor gobierno de la Corona, una en Aragón, otra en Valencia y una tercera para Cataluña, Mallorca, Córcega y Cerdeña ${ }^{38}$.

Jurista de reconocido prestigio, consejero real, vicecanciller, asesor de la Bailía ... Domingo Mascó tuvo también una importante relación con la Gobernación. La primera ocasión en que esto sucedía fue en mayo de 1385 cuando tras haber sido destituido de la Asesoría de esa institución Bernat d'Alpicat, a quien se le abrió una investigación, Pedro IV la concedió temporalmente a Mascó. El proceso contra Alpicat duró un año y en él no se encontró nada en su contra, con lo que en junio del año siguiente reingresaba a la Asesoría, que le era concedida de por vida ${ }^{39}$. Después de ejercer durante un año como asesor del portant veus de governador, Mascó siguió actuando como consejero y vicecanciller hasta primeros de 1392, en que accedió de nuevo a la Asesoría de la Gobernación tras el fallecimiento de Bernat d'Alpicat, cesando de su cargo como vicecanciller; así lo comunicaba Juan I a la reina el 23 de mayo de ese año ${ }^{40}$. No obstante, a los pocos meses Mascó renunció al ejercicio de la Asesoría, recayendo el oficio en otro doctor en leyes vecino de Valencia, Guillem Çaera, el 16 de septiembre ${ }^{41}$. Desconocemos la situación personal de Domingo Mascó en ese tiempo, pero es curioso que al poco de renunciar a un cargo tan importante como el de asesor de la Gobernación hiciese lo propio con el que venía ejerciendo desde 1381, el de abogado fiscal ${ }^{42}$. Algo sí que sabemos, y es que tras su nombramiento como asesor fue muy presionado para que renunciase a él, cosa que finalmente hizo. Tales presiones llegaron a conocimiento del rey, expresándolas en 1395 cuando le concedió por segunda ocasión dicho oficio. Mascó pasó a cupar el puesto de Çaera, que renunció a él debido, entre otras razones, a la gran cantidad de negocios, propios y extraños, que se atendían en la Curia de la Gobernación. Es así que desde el 31 de marzo de ese año se convirtió en asesor ordinario de la Gobernación ${ }^{43}$ con un salario anual de cuatro mil sueldos ${ }^{44}$, cargo al que unía el de asesor de la Bailía. En mayo de ese año recibió una ampliación de sus competencias como funcionario de la Gobernación, al obtener licencia para conocer y sentenciar todas las causas, tanto en primeras como en segundas apelaciones, que su superior no podía atender por estar ausente u ocupado en la resolución de otros procesos ${ }^{45}$.

Es importante señalar el respeto infundido por Mascó a toda la sociedad valenciana y órganos políticos de la Corona. Consideración que se hizo efectiva en las Cortes

38 ACA, C, reg. 1920 , f. 85 r.

39 ACA, C, reg. 978 , f. 68 r. (1386, junio, 22).

40 ACA, C, reg. 1962, f. $66 \mathrm{~V}$.

41 ACA, C, reg. 1921, f. 3r-v.

42 Le sucedió en el cargo Joan Mercader, doctor en leyes, quien junto a Ramon Tolsà quedaba como abogado fiscal de la ciudad y reino de Valencia. ACA, C, reg. 1921, If. 3v.-4r. (1393, enero, 9).

43 ACA, C, reg. 1921, f. 66v. (1395, marzo, 31). En este documento se dice que el nombramiento de 1392 se realizó en 22 de mayo.

44 ACA, C, reg. 1985, f. 19r.-v. (1395, mayo, 21).

45 ACA, C, reg. 1921, f. 69r. (1395, mayo, 21). 
de Valencia de 1403 cuando al fijarse fuero nuevo que impedía que nadie pudiese regir al mismo tiempo los oficios de la Gobernación y de la Bailía General o la Asesoría de ambas oficinas, se exceptuó de este supuesto a nuestro personaje ${ }^{46}$.

Al igual que otros notables juristas valencianos, Domingo Mascó se preocupó no sólo de la aplicación del Derecho, sino también de teorizar sobre él. Heredero directo de los postulados de Joan, de quien casi llegó a ser contemporáneo, Mascó fue ante todo un autor didáctico, un comentarista de la legislación que de forma sencilla y ordenada plasmó en papel considerandos jurídicos acerca de diversas cuestiones que por razones de tipo profesional le interesaban. Su gran conocimiento del Derecho y los años de ejercicio como profesional liberal y como asesor de las dos principales magistraturas del reino le convertían en una de las personas más indicadas para ello. Pese a las pocas posibilidades que brindaba la época, lo curioso es que Mascó fue un autor prolífico. Le conocemos un trabajo titulado Libre Negre de títols i privilegis. Commentaria super foris Valentie - muy al uso-, unas Alegacions sobre los fets o crims que.s fan o cometen en la mary un tercero que R. Narbona titula Tratado de la potestad y jurisdicción de la Bailía y Gobernación de esta ciudad y Reino ${ }^{47}$ y que es del que nos vamos a ocupar.

A primera vista el mentado Tratado de la postestad ... tenía como función principal aclarar en lo posible desde el plano jurisdiccional los continuos contenciosos entre Bailía y Gobernación. Nadie mejor que Mascó para intentarlo, pues como asesor de ambas Curias era quien mayores posibilidades tenía no sólo de elaborar el tan necesario catálogo de competencias razonadas de una y otra institución, sino más aun, y es que la solución por él arbitrada fuese aceptada por ambas partes en cuanto a que, en principio, no se le podía considerar persona sospechosa de parcialidad. Conocemos de un primer intento de alcanzar una concordia, aunque sin fecha, en que gobernador y baile general, asesorados ambos por Domingo Mascó y otros doctores, acuerdan observar en su totalidad el contenido de los tales privilegios y pragmáticas reales que expresaban la no existencia de superioridad de una magistratura con respecto a la otra y revocaban las comisiones sobre asuntos concernientes a sus teóricas competencias ordinarias. De tal modo que para evitar en lo posible las injerencias en la jurisdicción de cada oficio, en el supuesto caso de que uno de ellos obtuviese licencia real para proceder en causas que no correspondían a sus atribuciones ordinarias y sí a las del otro habrían de remitírselas independientemente del madato real ${ }^{48}$. Desde luego este pacto nos ofrece como conclusión primera que el habido años antes, 1376, no tuvo ningún efecto, pues en uno de sus puntos se convino eso mismo ${ }^{49}$.

Lo cierto es que frente al Stil de la Governació, el citado Tratado de Mascó no aparece en edición alguna de los fueros ni, que sepamos, en ningún catálogo de Derecho foral valenciano. Si bien, existe cierto documento en el Archivo del Reino de

46 Furs e Ordinations fetes ..., rúb. XLV, I, col. 2a ; p. 383.

47 NARBONA VIZCAÍNO, R., Gobierno politico y luchas sociales ..., I, p. 354.

48 ARV, $R$, reg. 687, ff. 102v. $-103 \mathrm{v}$.

49 CABEZUELO PLIEGO, J.V., «Un intento por resolver ..., p. 61. 
Valencia que quizá responda a esas características. Se trata de una declaración escrita del propio Domingo Mascó como asesor de la Gobernación y de la Bailía General del reino, posterior en todo caso a 1403, y que era poseída por Joan Mercader, baile general, en un libro con otras muchas provisiones tocantes a las competencias de la institución que gobernaba «fahents per la questió e debats de les jurisdiccións». Desconocemos si se trató de un encargo, como es el caso de Stil de Joan, o partió de la iniciativa de su autor a la vista de la problemática jurisdiccional. En el texto, estructurado sobre tres puntos, se reflexiona acerca de la jurisdicción al respecto de los musulmanes regnícolas, acerca de la posibilidad del titular de la Bailía de imponer multas y en tercer lugar sobre el ya mentado delito de resistencia contra oficiales reales. En lo concerniente a la primera cuestión, Mascó señala que la jurisdicción de «tots los moros» del reino «originariament e própia» pertenece al baile general, y que sobre ello existen varias provisiones y privilegios al respecto. Menciona uno fechado en Valencia, a 16 de abril de 1298, que es el origen de la vinculación de estas causas a la Bailía, donde se expone que las causas de los mudéjares habitantes en lugares de barones y caballeros habian de ser conocidas y sentencias por el procurador, "que huy a nom governador ${ }^{50}$. Posteriormente, a súplica de las ciudades y villas del reino y con fecha de Valencia, 1 de mayo de 1321, se estableció que las causas criminales existentes entre cristianos y moros de las que resultase pena de muerte o de mutilación de miembros habían de ser entregadas a los justicias ciudadanos. De todos modos Mascó apuntaba que en un libro de Bailía que se custodiaba en el Archivo Real de Barcelona se indicaba que el baile poseía la jurisdicción total sobre los judíos y los moros, quedando entre sus competencias la expedición de licencias a quienes pretendían acaptar limosna - argumentando las numerosas provisiones al respecto tanto como la propia legislación foral, tal y como se muestra en las Cortes de 1403-, o el castigo a aquellos moros del país encontrados sin el peinado denominado garçeta ${ }^{51}$, acerca de lo que ya se había legislado en tiempos de Pedro el Grande - 1 de diciembre de 1283-, sobre la mar y los navegantes, a la vez que le nominaba juez de las regalías. No obstante, sin duda debido a una normativa tan genérica, a Mascó le asaltaba la duda de a quíen correspondía la jurisdicción en el caso de que un moro de barón o de caballero delinquiese en una ciudad, villa o lugar de realengo o en territorio perteneciente a la Iglesia o a una Orden Militar. A su juicio la duda estaba en que en principio parace claro que tal causa había de quedar para el gobernador atendiendo al domicilio del delincuente, dado que las cuestiones sobre sarracenos de dominios laicos correspondían a este oficial según el privilegio de 1298. Alude también Mascó en apoyo de esta teoría a que se podría entender perteneciente a la Curia de la Gobernación «per rahó del dit delicte, car tot lo regne es territori del governador e axi on que delinqueixca lo moro delinqueis en son territorì. El problema surgió cuan-

50 Acerca de este privilegio y de su trascendencia cf. CABEZUELO PLIEGO, J.V., La Curia de la Procuración ..., p. 142 y ss.

51 En lo referente a este tipo de peinado cf. FERRER i MALLOL, M. ${ }^{2}$ T., Els sarraïns de la Corona catalano aragonesa en el segle XIV. Segregació i discriminació, Barcelona, 1987, pp. 45-55. 
do el rey sentenció apuntando que todos los asuntos de mudéjares delinquentes de barones y caballeros en el realengo y en lugares de la Iglesia y de religiosos fuesen conocidos y sentenciados por el baile general, tal y como se contenía en el mentado libro de Bailía. Es claro que el segundo privilegio anulaba al primero y que el oficial que se beneficiaba de ello era el baile en detrimento del portant veus, siguiendo una proyectada política real de vincular a las minorías con la Bailía. Si bien, fue en tiempos de Pedro el Ceremonioso cuando de nuevo la cuestión se suscitó para regresar a su antiguo juez, el procurador. Y ello, según Mascó, no se debió nada más que a las presiones del brazo militar que prefería que fuese la Procuración quien entendiese de tales asuntos en vez de la Bailía, sentenciándose en las Cortes de 1342. Con lo que se abría una vía de intervención foranea en una temática competencial de la Bailía. De esto, entendía Mascó, se derivaban dos conclusiones. La primera, que el baile general poseía jurisdicción sobre los sarracenos "habitants contrahents o delinquents» en el realengo valenciano y en los dominios de la Iglesia. Y la segunda que el gobernador no tenía jurisdicción sobre los moros habitantes en las ciudades, villas y lugares realengos $o$ a los pertenecientes a la Iglesia o a religiosos, incluidos sus términos, ni tampoco sobre los pertenecientes a barones y caballeros que hubiesen delinquido en ciudades, villas y lugares, y evidentemente en sus términos, tanto de realengo como de la Iglesia o de Órdenes Militares. Si bien, «en sus términos» habrá de entenderse como fuera del dominio de los barones, pues de existir en el término de una ciudad o villa real un señorío de barón o caballero, la jurisdicción sobre la causa de un musulmán habitante en ese señorío correspondería únicamente al gobernador y nunca al baile general.

La segunda de las cuestiones planteadas por Mascó en este breve trabajo, la posibilidad o no del baile de imponer multas por razón de su oficio, resultaba de lo más pertinente si atendemos a que el asunto originó ríos de tinta de dura polémica entre Bailía y Gobernación. Mascó, como era costumbre, comienza exponiendo las razones por las que, creía, que tradicionalmente se negaba a la Bailía tal derecho. Y éstas no eran otras que la consideración del oficio únicamente como de "administración», no de «jurisdicción», con lo que, en principio, se le negaba la posibilidad de la impositio mulctarum. No obstante, demuestra que los fueros reconocen a la Bailía capacidad jurisdiccional plena «in rebus patrimonialibus et fiscalibus», con lo que en casos de su competencia y atribución directa podrá, con o sin crida pública, imponer ese tipo de sanciones sin verse acosada por la Gobernación o cualquier otra magistratura del reino. Aunque, eso sí, sólo en el caso de que se le considerase poseedor de la jurisdicción, con lo que quedan exentos aquellos bailes que únicamente son colectores de los derechos reales.

Finalmente, el opúsculo plantea una tercera problemática, centrada en si el gobernador del territorio, "que per stil o pratiqua" conoce las causas de quienes han cometido delito de resistencia contra oficiales reales, puede también hacer lo propio con este tipo de faltas cuando son perpetradas contra el baile general e igualmente contra el resto de ordinarios de la Bailía. Las apariencias daban la razón al gobernador, al hacerse eco el propio Mascó de lo ocurrido a principios del Cuatrocientos en la villa 
de Chelva, donde por una resistencia realizada sobre el lugarteniente del baile general fue el portant veus de governador quien se encargó de punir a los culpables «cum exercitibus et manu fortim. Lo cierto es que lejos de lo que estos supuestos inducen a entender, Mascó argumenta por otro lado la independencia de la Bailía sobre cualesquiera otras instituciones regnícolas, limitada sólo por el dictamen real, lo que suponía que el baile general no conociese a otro superior que al rey. Por otro lado, el "superasesor» precisó que la intervención de la Gobernación en el asunto de la resistencia sobre un oficial de la Bailía en Chelva no devino de ordinario sino gracias a una licencia concedida por la Corona, es decir, se actuó por delegación -con lo que el presupuesto que defendía Guillem Ramon de Montcada ante Nicolau Pujada y que hemos visto líneas atrás se fundamentaba en una errata competencial-. Es por tal que su opinión fuese favorable a que desde la Bailía y por su titular se pudiesen conocer y sentenciar "resistencias et inobediencias factas sibi et officialibus suis, ut reperietis nullimode in regestris Curie Baiulie». 